\title{
Play Behavior in Crocodilians
}

\author{
Vladimir Dinets ${ }^{1^{*}}$ \\ ${ }^{1}$ University of Tennessee, Knoxville \\ *Corresponding author (Email: dinets@gmail.com)
}

Citation - Dinets, V. (2015). Play behavior in crocodilians. Animal Behavior and Cognition, 2(1), 49-55. doi: 10.12966/abc.02.04.2015

\begin{abstract}
Play behavior in crocodilians is not uncommon, but it remains virtually undescribed in scientific literature. I present the first overview of play behavior of three types (locomotor play, object play and social play) in crocodilians based on original observations, published reports and anecdotal evidence. Object play is the type most often reported; social play can include interactions with conspecifics and mammals. Apparently, play behavior is not particularly rare in crocodilians, but is underreported due to the difficulties of observing it and interpreting the observations.
\end{abstract}

Keywords - Alligator, Behavior, Caiman, Crocodile, Object, Play, Sociality

In the most comprehensive overview of play behavior in various animal taxa to date, Burghardt (2005) listed two published and three unpublished observations of apparent play in crocodilians, and suggested that such behavior would be reported more commonly if the animals were regularly observed under right conditions. So far, this prediction has been only partially correct in terms of published reports. As the number of crocodilians kept in captivity increased, and their behavior became the focus of much attention due to its previously underestimated complexity (Dinets, 2014a; Doody, Burghardt, \& Dinets, 2012), observations of play became more frequent, and its occurrence is now common knowledge among zoo keepers and crocodile farm personnel (A. Britton, personal communication, 2013; J. Brueggen, personal communication, 2014; S. Mukerjee, personal communication, 2013). However, despite numerous unpublished personal observations, no new reports of such behavior have appeared in scientific literature. Many aspects of crocodilian behavior remain poorly known due to their rare occurrence and to the difficulty of observing predominantly nocturnal predators (Dinets, 2014b), but in the case of play, an additional problem appears to be that people witnessing such behavior consider their observations unworthy of publishing or unlikely to be taken seriously.

Here I provide an overview of play behavior in crocodilians, compiled from my own observations and a variety of published and unpublished sources. I use the three-way classification of play (locomotor play, object play, and social play) as typically used in animal play research (Fagen, 1981).

\section{Materials and Methods}

The original observations were conducted opportunistically during over 3,000 $\mathrm{hr}$ of observing wild and captive crocodilians in the course of a study of crocodilian communication during the mating season (Dinets, 2013). Due to the aim of the study, focal animals were always adults. This might partially explain the small number $(N=7)$ of observed play occurrences, since in most other animals known to play, juveniles play more often than adults (Burghardt, 2005). 
To supplement the small number of personal observations, an informal survey of people working with crocodilians was conducted in 2013-2014 at various conferences and through social networks Twitter and Facebook (particularly Facebook groups Crocodile Conservation, Crocodiles in Captivity, and also Crocodile Specialist Group Facebook page). Conference audiences and social network users were asked to report their observations of behaviors that they thought or suspected could be play. Any explanation of what play might look like was avoided to prevent respondents from subconsciously adjusting their original evaluation of behaviors to better match the request. The respondents provided three reports mentioned below; additionally, 8 people stated that they had had such observations, but failed to provide any details. Due to the small number of records, data on all species are presented jointly; the species-by-species breakdown is provided in the Discussion.

\section{Locomotor Play}

Locomotor play was characterized by Burghardt (2005, p. 84) as performing "intense or sustained locomotor movements... often without any apparent immediate reason or stimulus." Being ambush predators with low metabolism level, crocodilians seldom engage in intense or sustained movements of any kind, so it is not surprising that this type of play is rarely observed. Burghardt (2005) quotes unpublished observations by Harry Green and Paul Weldon of captive young American alligators (Alligator mississippiensis) repeatedly sliding down slopes into water. A hatchling broad-snouted caiman (Caiman latirostris) kept in a concrete pool in Santa Cruz Zoo, Bolivia, would repeatedly approach a water bulge formed on the pool surface by an upward stream from an inflow pipe opening on the bottom and allow the outward current to carry it across the pool (J. Herrera, personal communication, 2007). Sunday Mail newspaper published (on November 3, 1996) observations and photos by Phil Cook of a $\sim 2.5 \mathrm{~m}$ long estuarine crocodile (Crocodylus porosus) repeatedly "surfing the waves" off a beach near Port Douglas, Australia.

\section{Object Play}

Object play appears to be the most frequently observed type of crocodilian play; it is so common that many zoo caretakers now provide various objects as toys for crocodilians as part of habitat enrichment programs.

Streams of water seem to be particularly popular play targets. Lazell and Spitzer (1977) reported an American alligator playing with water dripping from a pipe for at least $45 \mathrm{~min}$. The young alligator would swim around the dripping pipe, then turn to face the pipe. After watching for a few moments, the alligator would slowly pass towards, then veer away from the drip. It then began snapping at the drip as it cruised past it, sometimes allowing it to drip onto his head before biting at it. This behavior continued until the drip stopped. Heinbuch and Wiegmann (2000) observed juvenile Cuvier's dwarf caimans (Paleosuchus palpebrosus) repeatedly standing on their hind legs under a warm shower. The authors tried to elicit similar behavior from crocodilians of other species, but, although those animals seemed to enjoy the shower, they never assumed an upright position. It is possible that the dwarf caimans were playing with the water stream, although it could also be an instinctive attempt to orient oneself facing the current, as to be expected in a species adapted to life in relatively fast streams (Ross, 1992). I observed a young adult American alligator in Saint Augustine Alligator Farm Zoo Park (Florida, USA) moving its head horizontally back and forth across a stream of water falling from a pipe and making snapping movements as if trying to bite the stream. This behavior continued for over half an hour, sometimes interrupted with a few minutes of rest under the stream (Figure 1). 


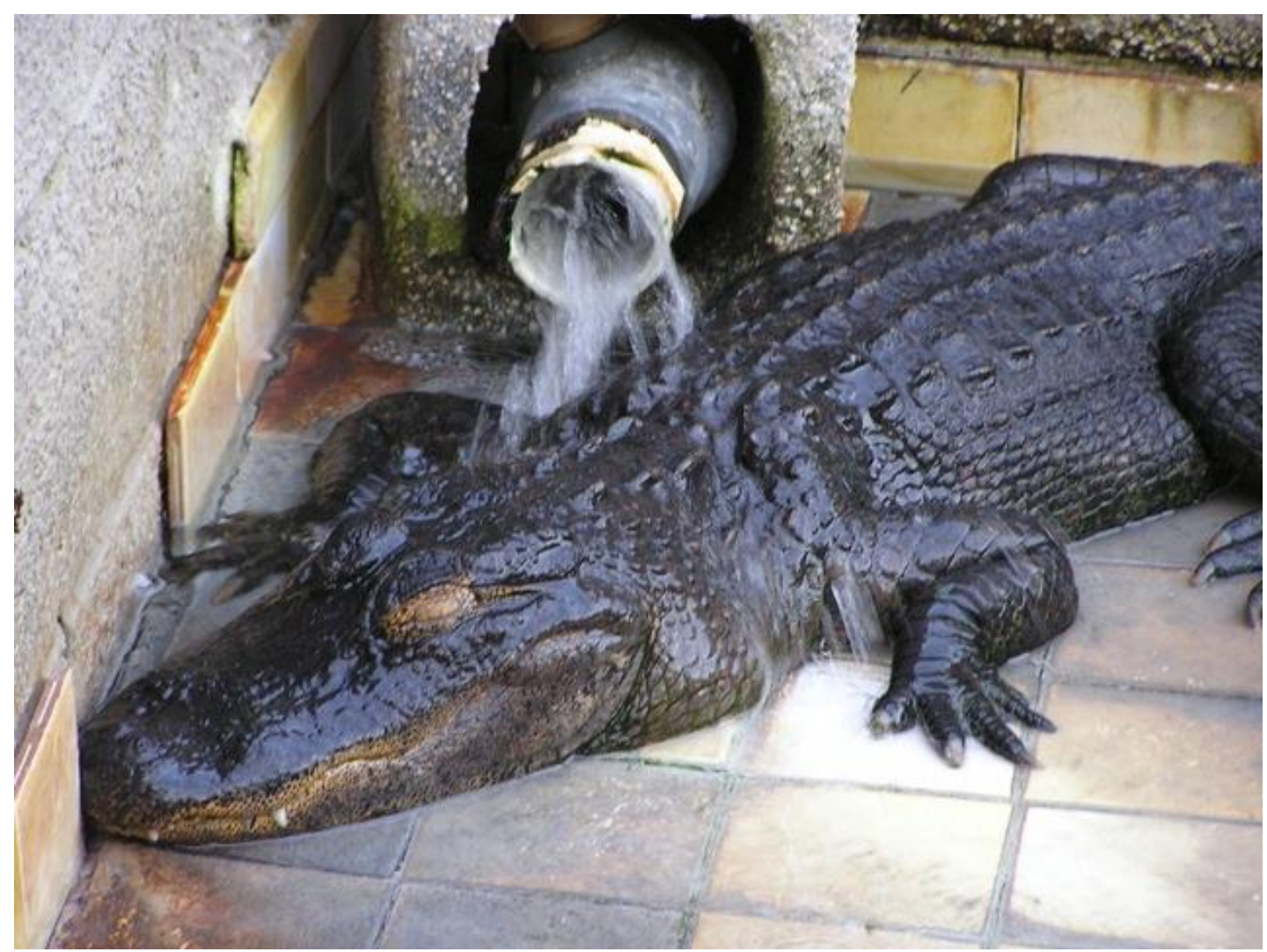

Figure 1. An American alligator (Alligator mississippiensis) resting after a bout of play with a stream of water, Saint Augustine Alligator Farm Zoo Park, Florida, USA.

Another category of object play is interacting with various floating objects, often provisioned toys or commercial enrichment items. Burghardt (2005, p. 283) quotes Andrew Odum at the Toledo Zoo, who observed a male Cuban crocodile (Crocodylus rhombifer) "attacking and pushing around a large ball and approaching it while blowing bubbles used in courtship." There is no reason to think that the male was actually trying to court the ball, since attack behavior was also involved. A video of a large male estuarine crocodile playing with a ball, filmed by John Brueggen at Saint Augustine Crocodile Farm Zoo, can be seen at http://youtu.be/DuwUtKhQCf0. The video might look like feeding response, but the crocodile has been playing with that particular ball for years (J. Brueggen, personal communication, 2015). Adult crocodilians of many species can often be seen pushing twigs, grass and other floating vegetation while swimming (personal observations). In many cases this behavior appears to be accidental, but on two occasions I have seen crocodilians doing this in a manner strongly suggesting play. In both cases, the objects were pink Bougainvillea flowers that were floating in the pools where the animals were kept captive. Adult male Cuban crocodile in Zoo Miami (Florida, USA) manipulated such flowers repeatedly over seven days of observation, picking them up, pushing around, and carrying in the teeth or on the tip of the snout (Figure 2A). An adult West African dwarf crocodile (Osteolaemus cf. tetraspis) in Madras Crocodile Bank (Tamil Nadu, India) behaved in exactly the same way (Figure 2B). In both cases, there was a variety of other small objects floating in the pools (small green and yellow dry leaves and white flower petals in Zoo Miami; yellow dry leaves and white egret feathers of varying size in Madras Crocodile Bank), but these objects were completely ignored. Anecdotal observations suggest that crocodilians are generally attracted to small pink objects, and prefer them over similar objects of other colors for biting and manipulating (J. Harding, personal communication, 2014). However, a floating or submerged object of any color, if left in an enclosure with captive crocodilians, is likely to be repeatedly 
bitten and severely damaged sooner or later (John Brueggen, personal communication, 2008; Patty Register, personal communication, 2009).

A)

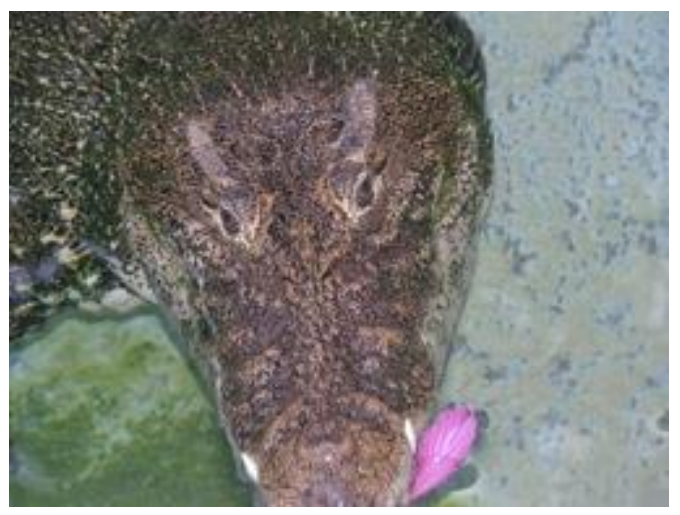

B)

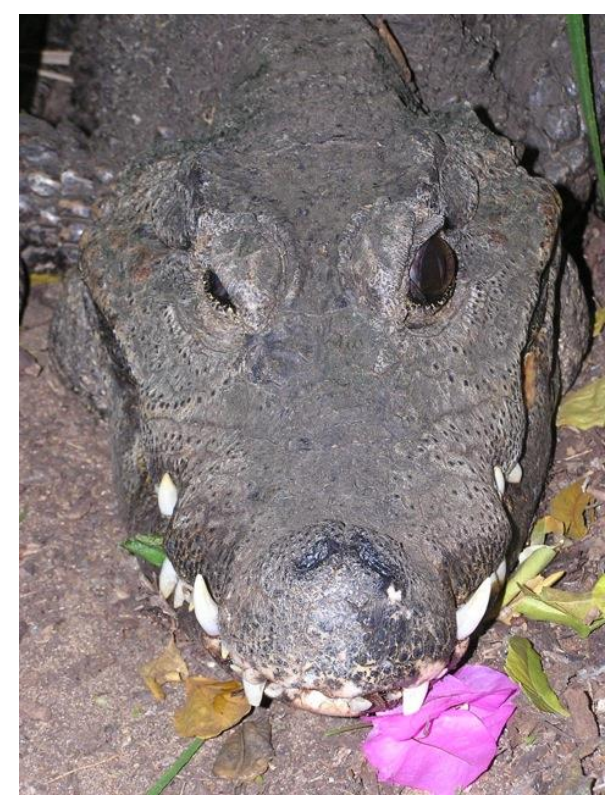

Figure 2. Crocodiles playing with Bougainvillea flowers. A) Cuban crocodile (Crocodylus rhombifer) in Zoo Miami, Florida, USA. B) West African dwarf crocodile (Osteolaemus cf. tetraspis), Madras Crocodile Bank, Tamil Nadu, India.

Not all object play takes place in the water. Lani Lyman-Henley (personal communication, 2014) reported observing the following behavior in human-raised, very tame juvenile American alligators kept in a residential house (her interpretations of observations are quoted verbatim):

When cleaning their tank, I'd put them in the bathtub. When they'd gotten pretty big, they'd splash around for a bit, then climb out of the tub and I'd find them hanging out on the tiled floor. One time I heard clattering noises in that bathroom, but when I opened the door to look, they froze, and were just sitting still on the floor looking at me. I left, listening at the door. The clattering started again after a few minutes, and I swept in to try to catch them in the act. Again, froze. But I watched as one of them, staring right at me, slowly dropped a ceramic dome from the corner of his mouth...and I realized what it was. They had knocked the ceramic caps off the screws of the toilet base, and I can only guess that they were knocking them around the room. And one of them had one in his mouth... I never could catch them at it again. I mean, they were really making noise, had to be knocking that thing against the walls and tub! But the "I wasn't doing anything" expression was just priceless.

Crocodilians also play with prey items. Divyabhanusinh (1986) observed and photographed a mugger crocodile (Crocodylus palustris) apparently playing with a dead and partially eaten sambar deer (Cervus unicolor). The crocodile grabbed the carcass by the neck and spinned five or six times as if trying to dismember the carcass. It stopped with its feet in the air, then slowly rolled over onto its feet, released the carcass and walked away without eating any of it. The Telegraph newspaper published (on August 9, 2014) the observations and photographs by Roland Ross of a large Nile crocodile (Crocodylus niloticus) playing with a dead hippopotamus (Hippopotamus amphibius) calf. The crocodile spent 25 min repeatedly throwing the carcass in the air, "spinning and jumping and splashing." It is unknown if the calf had been killed by the crocodile or died from other causes. 


\section{Social Play}

Social play by crocodilians is almost never reported, but this doesn't mean that it is particularly rare. There is a "short sequence of film of two sibling Nile crocodiles tussling with one another in what looked like play behaviour" (D. Naish, personal communication, 2013). I have observed two juvenile black caimans (Melanosuchus niger) about $30 \mathrm{~cm}$ long in Mamiraua Reserve (Brazil) as they swam in a tight circle as if chasing each other; this behavior occurred in three bouts of $\sim 1$ min each during one night of observation. Similar behavior is often displayed by adult crocodilians during courtship (Dinets, 2010); indeed, in other vertebrate species it is quite common for elements of courtship behavior to be incorporated into play by juveniles as well as adults (Burghardt, 2005). Conversely, courtship might involve elements of play that are often difficult to recognize as such. I observed and photographed a pair of adult Cuban crocodiles at Zoo Miami performing a particularly unusual behavior at the time of courtship: the female would get on the back of the larger male, and he would give her a few rides around the pool (Dinets, 2011). At the time of observation I interpreted this behavior as part of regular courtship, but apparently it has never been seen in other courting pairs of Cuban crocodiles in the wild or in captivity, so it could be a form of play developed by this pair during many years of living together. In Fakahatchee Strand Preserve (Florida, USA) I observed a somewhat similar behavior in a mixed crèche of hatchling American alligators from two broods of different age: on three occasions in one morning of observation, a younger alligator took a short ride on the back of an older one (Figure 3).

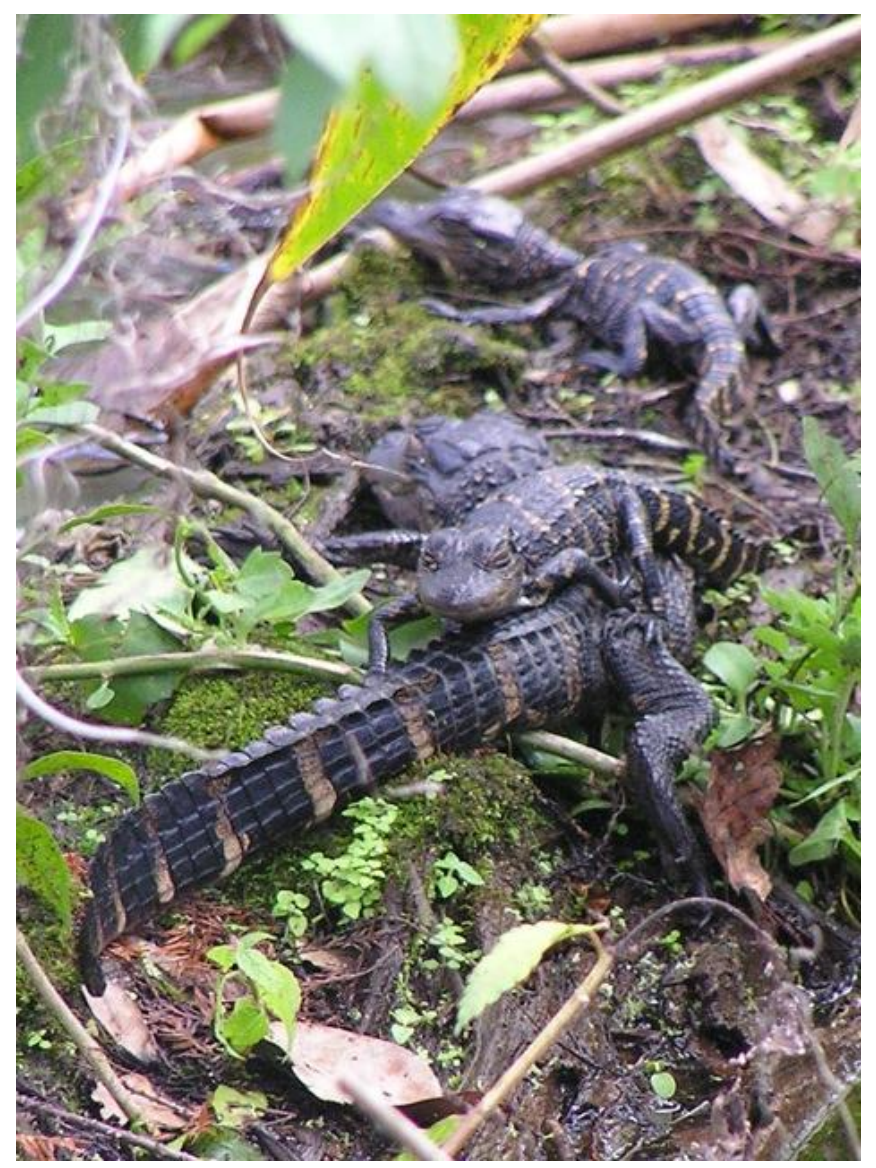

Figure 3. A hatchling American alligator (Alligator mississippiensis) riding on the back of an older individual in a multi-brood crèche, Fakahatchee Strand Perserve, Florida, USA.

An American crocodile (Crocodylus acutus), rescued and named Pocho by Gilberto 'Chito' Shedden, became a celebrity in Costa Rica for being absolutely tame and very playful with its rescuer. 
Their unique relationship continued for $20 \mathrm{yrs}$, until the crocodile died apparently of old age. Play behavior included swimming together, rushing at Shedden with an open mouth in mock charges, sneaking on him from behind as if to startle him, and accepting being caressed, hugged, rotated in the water and kissed on the snout (G. Shedden, personal communication, 2004; also personal observations). Pocho's behavior was seen by thousands of tourists, filmed countless times (including a full-length documentary The Man Who Swims With Crocodiles by Roger Horix), and featured by most Central American newspapers, but it has never been mentioned in scientific literature; the only published source of detailed information is a Wikipedia article.

I observed apparent interspecific play between an American alligator and a river otter (Lontra canadensis) in Big Cypress National Preserve (Florida, USA), in a bayou inhabited by 8-12 subadult alligators and regularly visited by a group of 4-6 otters. The otters would often harass the alligators by approaching them closely, nipping on their tail tips, and splashing water onto their heads. Most alligators responded to harassment by submerging, but one individual $\sim 1.5 \mathrm{~m}$ long responded by lunging at the otters every time they got close. By the third day of observation the otters focused most of their attention on that individual. On one occasion an otter slipped on a steep bank of the bayou and was grabbed across the chest by the alligator. The alligator retreated from the bank and pulled the wriggling otter underwater as if attempting to drown it, but after about $5 \mathrm{~s}$ raised its head and released the otter, apparently unharmed. The interactions between this alligator and the otters then continued for two more days, at which point the bayou dried out and all otters and alligators moved elsewhere.

\section{Discussion}

Burghardt (2005, pp. 70-78) proposed five criteria for recognizing a behavior as play, and noted that a behavior can be recognized as play even if it doesn't match all five. The criteria are as follows:

1. The performance of the behavior is not fully functional in the form or context in which it is expressed; that is, it includes elements, or is directed towards stimuli, that do not contribute to current survival.

2. The behavior is spontaneous, voluntary, intentional, pleasurable, rewarding, reinforcing, or autotelic (done for its own sake).

3. It differs from the "serious" performance of ethotypic behavior structurally or temporally in at least one respect: it is incomplete (generally through inhibited or dropped final element), exaggerated, awkward, or precocious; or it involves behavior patterns with modified form, sequencing, or targeting.

4. The behavior is performed repeatedly in a similar, but not rigidly stereotyped, form during at least a portion of the animal's ontogeny.

5. The behavior is initiated when the animal is adequately fed, healthy, relaxed, and free from stress (e. g. predator threat, harsh microclimate, social instability) or intense competing systems (e. g. feeding, mating, predator avoidance).

Many observations described above match most of Burghardt's five criteria. For example, trying to "catch" a stream of water is not a functional predatory behavior (criterion 1); sliding down steep slopes appears to be "spontaneous, voluntary, intentional, pleasurable, rewarding, reinforcing, or autotelic" (criterion 2); releasing a captured otter seems to be a good example of incomplete behavior (criterion 3); most observations were of repeated behaviors (criterion 4) performed by animals in comfortable, relaxed situations (criterion 5). Even though these observations of apparent play behavior are mostly singular and, if taken separately, allow for alternative explanations (some of which are mentioned in Results section), combined they present strong evidence that play might be a more regular part of crocodilian behavioral repertoire than currently recognized. As Burghardt (2005) points out, this is to be expected in animals with complex, flexible behavior. However, he also makes the important point that energetic constraints reduce the probability of observing sustained vigorous behavior typical of endothermic mammals and 
birds in ectothermic vertebrates. On the other hand, aquatic environment reduces the cost of locomotion, possibly facilitating the performance of play in crocodilians (Burghardt, Ward, \& Rosscoe, 1996). Indeed, the most vigorous of the behaviors listed above ("surfing," mock charges) took place in the water.

The 17 records of possible play behavior listed above involve 10 species of crocodilians (6 records for the American alligator, 3 records for the Cuban crocodile and 1 record for every other species). It is possible that alligators are involved in play more often than crocodiles because they are more social (Ross, 1992), but it is far more likely that these numbers reflect nothing more than observational coverage bias and the randomness of rare observation events.

So, how often do crocodilians play? To answer this question, we need a much better understanding of crocodilian social interactions and behavioral repertoire in general; that would allow us to better recognize play when we see it.

\section{Acknowledgments}

I thank Adam Britton, John Brueggen, Joan Harding, Jesus Herrera, Lani Lyman-Henley, Sokham Mukerjee, Patty Register, and Gilberto Shedden for sharing their observations; IUCN Crocodile Specialist Group and Darren Naish for help with collecting information; and Gordon Burghardt and the anonymous reviewers for editorial advice.

\section{References}

Burghardt, G. M. (2005). The Genesis of Animal Play: Testing the Limits. London: The MIT Press.

Burghardt, G. M., Ward, B., \& Rosscoe, R. (1996). Problem of reptile play: Environmental enrichment and play behavior in a captive Nile soft-shelled turtle (Trionyx triunguis). Zoo Biology, 15, 223-228.

Dinets, V. (2010). Nocturnal behavior of the American alligator (Alligator mississippiensis) in the wild during the mating season. Herpetological Bulletin, 111, 4-11.

Dinets, V. (2011). Crocodylus rhombifer (Cuban crocodile) mating behavior. Herpetological Review, $42,232$.

Dinets, V. (2013). Long-distance signaling in extant crocodilians. Copeia, 517-526.

Dinets, V. (2014a). Apparent coordination and collaboration in cooperatively hunting crocodilians. Ethology Ecology \& Evolution, doi: 10.1080/03949370.2014.915432.

Dinets, V. (2014b). Dragon songs. Love and adventure among crocodiles, alligators and other dinosaur relations. New York: Arcade.

Divyabhanusinh. (1986). Note on the strange behavior of a marsh crocodile (Crocodylus palustris). Journal of the Bombay Natural History Society, 83 (Supplement), 220-221.

Doody, J. S., Burghardt, G. M., \& Dinets, V. (2012). Breaking the social-non-social dichotomy: A role for reptiles in vertebrate social behavior research? Ethology, 119, 1-9.

Fagen, R. (1981). Animal play behavior. New York: Oxford University Press.

Heinbuch, B., \& Wiegman, T. (2000). Unusual behavior of dwarf caiman. Crocodile Specialist Group Newsletter, 19, 14-15.

Lazell, J. D. Jr., \& Spitzer, N. C. (1977). Apparent play behavior in an American alligator. Copeia, 188.

Ross, C. A. (1992). Crocodiles and alligators. Melbourne: Blitz. 